\title{
Millimeter Wave Extended Interaction Oscillator Based on Pseudospark-sourced Electron Beam
}

\author{
Huabi Yin, Liang Zhang, Wenlong He, Guoxiang Shu, \\ Adrian Cross and Alan Phelps \\ Department of Physics, SUPA, University of Strathclyde \\ Glasgow, Scotland, UK, G4 0NG \\ h.yin@strath.ac.uk
}

\author{
Yong Yin \\ School of Physical Electronics, University of Electronic \\ Science and Technology of China, Chengdu, 610054, China
}

\begin{abstract}
In this paper the study of a W-band extended interaction oscillator based on a pseudospark-sourced electron beam will be presented. This new device successfully produced a peak output power of over $38 \mathrm{~W}$, which agrees well with the prediction from the 3D particle-in-cell simulation. It displays the outstanding features of compactness and cost-effectiveness. The main contributing factors include the transport of the electron beam by the positive ion focusing channel without the need of an external guiding magnetic field and high interaction impedance and high gain per unit length of the extended interaction oscillator circuit.
\end{abstract}

Keywords-extended interaction oscillator; pseudospark discharge; electron beam;

\section{INTRODUCTION}

At millimeter and sub-millimeter wavelengths (terahertz frequencies), the achievable output power of the conventional "O" type vacuum electronic devices are greatly limited by the electron beam current that can be transported through the device at a particular voltage. The current density of a pseudospark-sourced electron beam is of the order of hundreds of amps per $\mathrm{cm}^{2}$ or higher $[1,2]$, which enables a wide range of applications in generating millimeter and sub-millimetre wave radiation $[3,4]$.

A pseudospark discharge is a three-phase process happening in an unique hollow cathode structure within a certain low pressure range (typically 50-500 mTorr). During a pseudospark discharge, low temperature plasma is formed that acts as a virtual cathode for extraction of high-quality electron beams of diameters in the range from millimetres to microns [5-9]. The electron beam has the ability of self-focusing due to the unique structure and the formation of an ion channel generated by the beam front. Simulations have shown that the pseudospark plasma sourced electron beam would propagate within background plasma of density in the range of $10^{14}-10^{16} \mathrm{~m}^{-3}$ without any applied guiding magnetic field. The production and propagation of higher current-density electron beams, compared to thermionic cathodes, from pseudospark discharges have been convincingly demonstrated [6]. This makes it an excellent electron beam source for compact millimetre-wave devices.
In this paper, a W-band extended interaction oscillator (EIO) driven by pseudospark-sourced electron beam is presented.

\section{MiLlimeter WAVE EIO}

A W-band (75 GHz-110 GHz) EIO circuit operated in the $2 \pi$ mode was selected for the first experiment because of its shorter interaction length, high interaction impedance and high gain per unit length [10], as compared with a backward wave oscillator. The beam voltage was designed to be centered at $30.5 \mathrm{kV}$, which is suitable for a four-gap pseudospark discharge. This newly developed device combines the merit of a short interaction circuit in the EIO and the high current density property of the pseudospark-sourced electron beam to generate W-band coherent radiation. Experimental results show that with a $35 \mathrm{kV}$ discharge voltage, the EIO successfully produced W-band radiation pulses with $38 \mathrm{~W}$ peak power and $20 \mathrm{~ns}$ duration, which agrees well with the $3 \mathrm{D}$ Particle-in-Cell (PIC) simulations using MAGIC.

A photograph of the W-band oscillator based on a pseudospark-sourced electron beam and the EIO circuit which includes a schematic drawing of the experiment are shown in Fig. 1. It does not need an external focusing magnetic field and is capable of operating at high repetition rate (up to a few $\mathrm{kHz}$ ) [11]. Fig. 2 shows the layout, dispersion and pictures of the EIO circuit, from which the EIO structure and operating frequency can be seen.

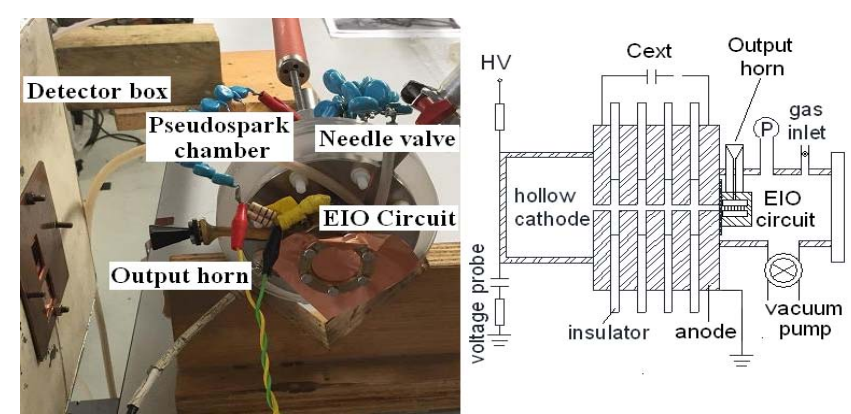

Fig. 1. Experimental setup of the W-band EIO based on a pseudosparksourced electron beam and the schematic drawing of the experiment.. 

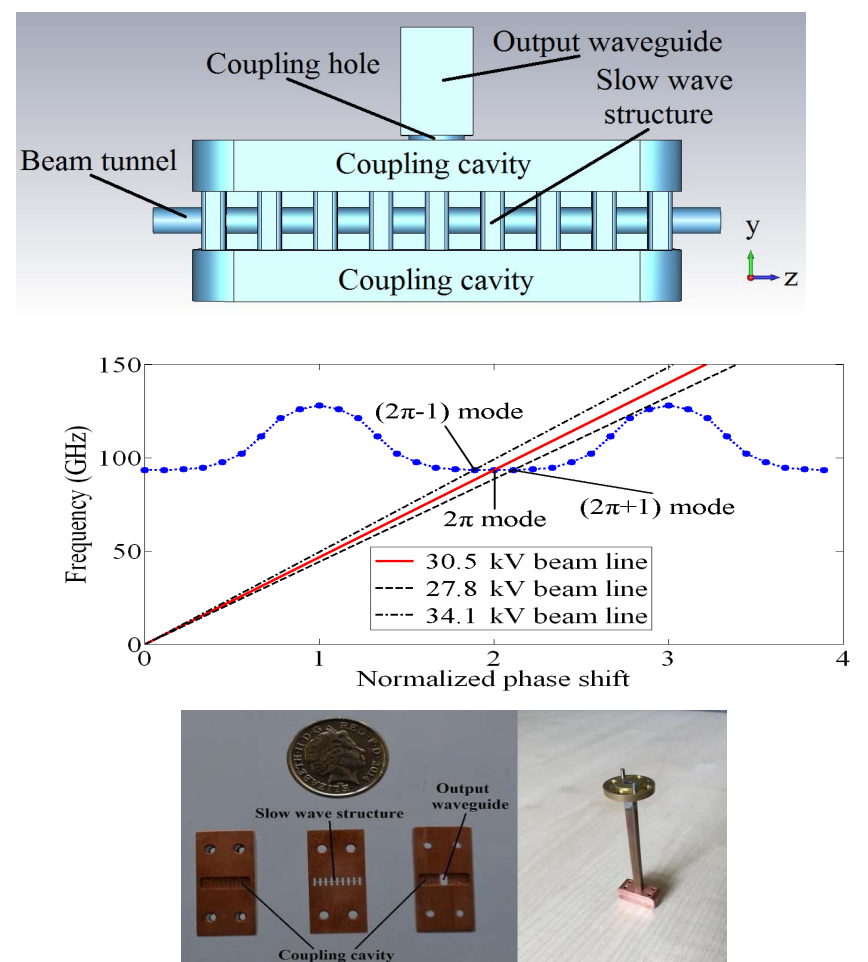

Fig. 2. The layout (top), dispersion (middle) and pictures (bottom) of the EIO circuit.

\section{EXPERIMENTAL RESULTS AND ANALYSIS}

Experimental measurements of the W-band EIO based on the pseudospark-sourced electron beam were carried out at the University of Strathclyde. A four-gap pseudospark discharge chamber which can hold-off a discharge voltage up to $40 \mathrm{kV}$ was used. The discharge voltage swept from $38 \mathrm{kV}$ to $25 \mathrm{kV}$ to achieve the maximum output power. Two W-band horns, one for the output from the EIO and the second horn for the microwave detector, were used. The two horns were separated by a distance of $20 \mathrm{~cm}$. The microwave radiation pulse was measured by a W-band crystal detector. A typical measurement of the voltage, beam current and the microwave signal are shown in Fig. 3. The duration of the microwave waveform agrees well with the simulation.

To estimate the radiation power, the crystal detector was calibrated using a $1.5 \mathrm{~W}, 90-97 \mathrm{GHz}$ solid-state source. The response of the detector at different output powers was recorded. From the calibration data, the radiation power was obtained from the amplitude of the crystal detector output. The peak power of the radiation was found to be about $\sim 38 \mathrm{~W}$. The output frequency was examined using a high pass waveguide cutoff filter which operated above $92 \mathrm{GHz}$. The radiation frequency was found to be above $92 \mathrm{GHz}$ which also coincides with the VNA millimeter wave measurement result of $93.8 \mathrm{GHz}$. A literature review indicates this is the first experiment of an EIO based on a pseudospark-sourced electron beam. It provides a compact and affordable way to generate tens of watts in W-band. Future work will explore a W-band sheet-beam EIO for further output power enhancement.
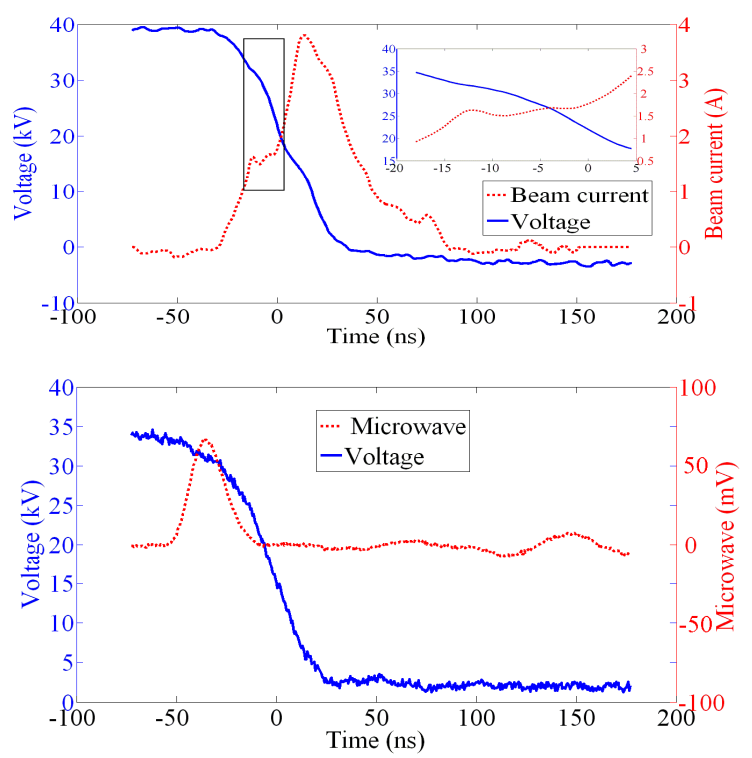

Fig.3. Typical waveforms of the electron beam current, voltage and the microwave pulse.

\section{REFERENCES}

[1] D. Bowes, H. Yin, W. He, K. Ronald, A. D. R. Phelps, D. F. Chen, P. Zhang, X. D. Chen, D. H. Li, and A.W. Cross, "Visualization of a Pseudospark-Sourced Electron Beam". IEEE Trans. Plasma Sci., vol. 42, pp. 2826-2827, Oct. 2014

[2] D. Bowes, H. Yin, W. He, L. Zhang, A. W. Cross, K. Ronald, A. D. R. Phelps, D. Chen, P. Zhang, and X. Chen, "X-ray emission as a diagnostic from pseudospark-sourced electron beams", Nucl. Instrum. Methods Phys. Res. B, vol. 335, pp.74-77, Sept. 2014.

[3] A. W. Cross, H. Yin, W. He, K. Ronald, A. D. R. Phelps, and L. C. Pitchford, "Generation and application of pseudospark-sourced electron beams," J. Phys. D: Appl. Phys., vol. 40, pp. 1953-1956, Jul. 2007.

[4] H. Yin, A. W. Cross, W. He, A. D. R. Phelps, K. Ronald, D. Bowes, and C. W. Robertson, "Millimeter wave generation from a pseudosparsourced electron beam", Phys. Plasmas, vol. 16, 063105, June 2009.

[5] N. Kumar, D. K. Verma, J. Prajapati, M. Kumar, B. L. Meena, M. S. Tyagi, V. Srivastava, and U. N. Pal, "Experimental Investigation of Pseudospark generated electron beam" J. Phys.: Conf. Ser., vol. 390, 012073, 2012.

[6] H. Yin, A. W. Cross, A. D. R. Phelps, et al. "Propagation and postacceleration of a pseudospark-sourced electron beam " Appl. Phys. Lett., vol. 91, no.8, pp. 5419-5422, Apr. 2002.

[7] Jia Zhang, Junping Zhao, Qiaogen Zhang, "Fast Electron Ionization Effect in Multigap Pseudospark Discharge Under Nanosecond Pulsed Voltages", IEEE Trans. Plasma Sci., vol.43, pp. 3921-3924, Nov. 2015.

[8] J. Zhao, H. Yin, L. Zhang, G. Shu, W. He, J. Zhang, Q. Zhang, A. D. R. Phelps, and A. W. Cross, "Influence of the electrode gap separation on the pseudospark-sourced electron beam generation," Phys. Plasmas, vol. 23, 073116, July 2016.

[9] W. He, L. Zhang, D. Bowes, H. Yin, K. Ronald, A. D. R. Phelps, and A. W. Cross, "Generation of broadband terahertz radiation using a backward wave oscillator and pseudospark-sourced electron beam," Appl. Phys. Lett., vol. 107, no. 13, 133501, Sept. 2015.

[10] Y. Yin, W. He, L. Zhang, H. Yin, C. W. Robertson and A. W. Cross, "Simulation and Experiments of a W-band Extended Interaction Oscillator based on a pseudospark-sourced electron beam," IEEE Trans. Electron Devices, vol. 63, no. 1, pp. 512 - 516, Jan. 2016.

[11] A. E. Dubinov, I. L. L'vov, S. A. Sadovoy, V. D. Selemir, D. V. Vyalykh, and V. S. Zhdanov, "Ultraminiature pulsed periodic generator of powerful microwave pulses, based on gas discharge in hollow cathode," IEEE Trans. Plasma Sci., vol. 40, pp. 2079-2082, Aug. 2012. 